\title{
Prefacio
}

\section{J. Morales}

Ante todo quiero expresar mi más sincero agradecimiento a todos los que han participado en este volumen homenaje a Dolores Soria, muchas gracias por vuestro esfuerzo y por la comprensión mostrada a lo largo de la elaboración del libro. También expresar mi gratitud a José López Ruiz —editor de Estudios Geológicos cuando se fraguó la iniciativa de dedicar un volumen homenaje a nuestra compañera- que apoyó la idea desde el primer momento y al actual editor de la revista, José María Cebriá, por su incondicional ayuda. Agradecimiento especial a Luis Gómez Argüero por su dedicación y esfuerzo desde la secretaría de la revista, haciendo un trabajo anónimo, pero eficaz. Todos tenemos la suerte de contar con la aportación de Emiliano Aguirre, lo que en un libro como este, que tiene su grado de tristeza, es una gran alegría.

El propio Emiliano Aguirre ha resumido más adelante la vida científica de Dolores Soria, particularmente quiero resaltar varios aspectos que pueden ayudar a entender cómo era ella y aquello que perseguía.

Por una parte, fue una mujer valiente, que no dudaba en embarcarse en cualquier aventura paleontológica, le gustaba viajar y conocer lo desconocido, disfrutaba en el campo y siempre mantenía una simpatía y saber estar impecables, en cualquier lugar y situación por dura o incómoda que fuese. Verdaderamente en su faceta humana Dolores Soria fue una persona fuera de lo corriente.

Por otra parte, en su labor de investigación alcanzó dos grandes logros. Uno, fue capaz durante cerca de tres lustros de aglutinar en proyectos de investigación a muchos de los investigadores españoles interesados en el estudio de los rumiantes. Creo que prácticamente la totalidad de los investigadores españoles dedicados al estudio de estos mamíferos fósiles hemos participado una o varias veces en los proyectos que ella dirigió con éxito y generosidad. Dos, se atrevió a estudiar el esqueleto postcraneal de los rumiantes fósiles, un reto difícil, tanto por la escasez de estudios previos, como por la falta en
España de buenas colecciones de comparación. Desde el ya lejano estudio de los rumiantes del yacimiento de Los Valles de Fuentidueña, publicado en un volumen monográfico de Estudios Geológicos en 1981, hasta la monografía de los yacimientos de Sperrgebiet, que pronto saldrá a la luz, ella hizo un gran esfuerzo en la investigación de los rumiantes de los yacimientos del Mioceno de Eurasia y África. Dolores Soria, sin duda, ha puesto una firme base para que algunos de nosotros podamos continuar investigando en uno de los temas más atractivos de la paleontología de mamíferos.

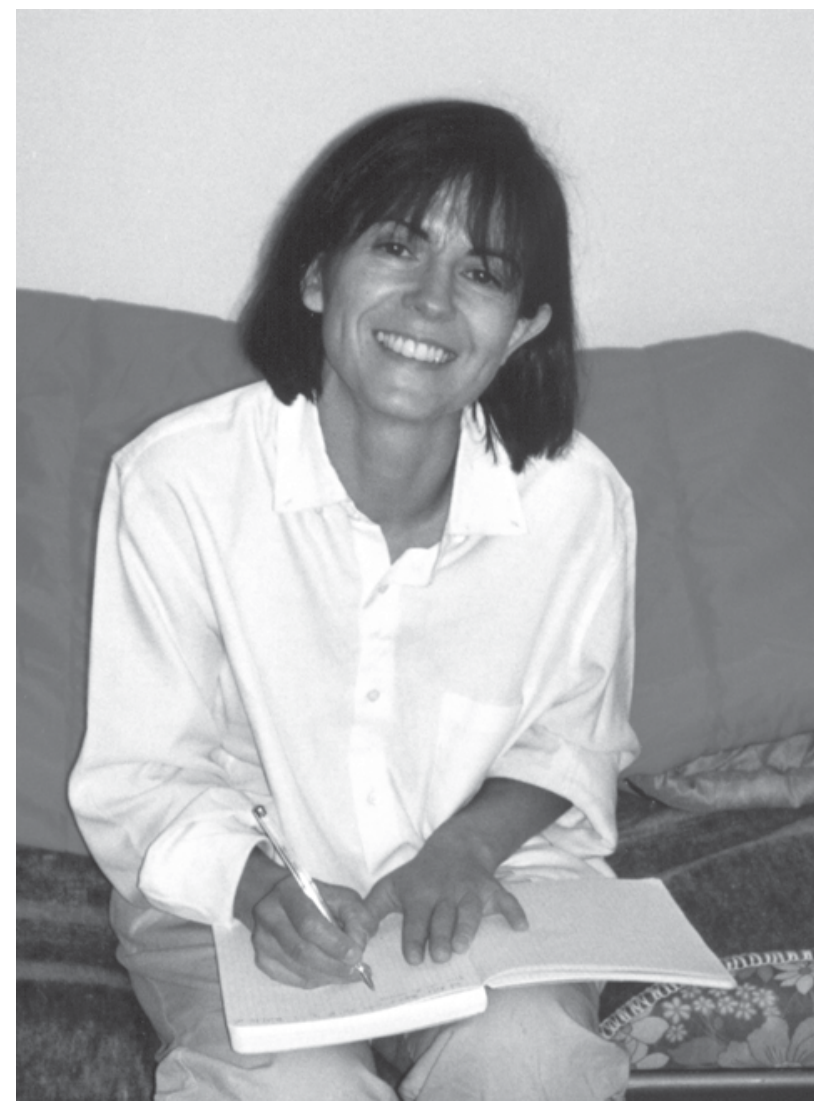

María Dolores Soria Mayor (1948-2004). 